\section{PENELITIAN UNTUK ROL KARET GILINGAN PAD}

by : Herminiwati, Arum Yuniari, Adi. S

\section{ABSTRACT}

8 (eight) samples of different trade-mark of Rice hulling rubber rolls that consist of four types of roll size, the colour of which are grey, dark green and brown are tested for the purpose of this research. The roll testing method and technical specification is taken from Indian Standard and Japanese Industrial Standard. The test results of physical properties which ted as the decisive factor of the quality are as follow : thickness $18,54 \mathrm{~mm}-21,60 \mathrm{~mm}$, tensile strength $10,85 \mathrm{~N} / \mathrm{mm}^{2}-16,65 \mathrm{~N} /$ $\mathrm{mm}^{2}$ elongation at ming 87 - elongation at break $106,8 \%-258,0 \%$, hardness before aging 87 - 95 Shore $A$ and after aging 82 - 92 Shore A, abrasion resistance (Grasselli) $0,070 \mathrm{~mm}^{3} / \mathrm{kgm}-0,790 \mathrm{~mm}^{3} / \mathrm{kgm}$.

\section{PENELITIAN MUTU ROL KARET GILINGAN PADI}

Oleh : Herminiwati, Arum Yuniari, dan Adi S

\section{INTISARI}

Dalam penelitian ini telah diuji 8 buah merk rol karet gilingan padi yang meliputi 4 tipe ukuran rol, dengan warna abu-abu, hijau tua dan coklat. Metoda pengujian dan spesifikasi teknis untuk rol berdasar pada Indian Standard dan Japanese Industrial standard. Adapun hasil uji sifat-sifat fisika yang ditetapkan sebagai faktor penentu mutu adalah sebagai berikut : tebal 18,54 - 21,60, tegang an putus $10,85 \mathrm{~N} / \mathrm{mm}^{2}-16,65 \mathrm{~N} / \mathrm{mm}^{2}$, perpanjangan putus $98,7 \%$ - 258,0\% , kekerasan sebelum pengusangan 87 - 95 Shore setelah pengusangan $82-92$ Shore A, Ketahanan Kikis Grasselli $0,07-0,790 \mathrm{~mm}^{3} / \mathrm{kgm}$

\section{PENELITIAN MUTU ROL KARET GILINGAN PADI}

\section{PENDAHULUAN}

Rol karet gilingan padi merupakan salah satui komponen penting dari mesin pengupas gabah ( rice huller) yang berfungsi sebagai pemecah/pengupas kulit gabah.

Saat ini rol tersebut telah banyak diproduksi dan dapat $d$ jumpai di pasaran dengan berbagai merk dan kwalitas, Demikian pula mesinnyapun telah diproduksi di dalam negri dan bahkan untuk keperluan ini telah ditetapkan cara pengujian mesin tersebut sebagai SII. 1021-84, Cara Uji Unjuk Kerja Mesin Pengupas Gabah Rol Karet, maka untuk menunjang hasil kerja mesin tersebut diperlukan tersedianya rol karet yang mutunya terjamin dan dapat berfungsi sebagaimana mestinya.

Rol karet gilingan padi terdiri dari 2 bagian yang penting, yakn rol karet dan rol logam. Bagian rol karet mudah menjadi aus didalam penggunaannya sehingga harus sering diganti, maka rol karet yang cukup tersedia, mudah didapat dan diganti sangatlah diperlukan. Oleh karena itu perlu dilakukan penelitian dan pengujian terhadap rol karet tersebut untuk menentukan persyaratan agar dapat menjamin penggunaannya.

\section{TINJAUAN PUSTAKA}

Rol karet gilingan padi terbuat dari kompon karet alam, sintetis atau campurannya yang dipres dan direkatkan pada rol logam serta divulkanisasi. Bahan tidak boleh mengandung scrap atau reclaimed rubber, sedangkan rol logam terbuat dari besi tuang atau baja.

Rol karet gilingan padi yang diproduksi dan banyak terdapat di pasaran saat ini terdapat dalam 4 tipe ukuran sesuai dengan kapasitas mesin yang diproduksi, yakni tipe I rol dengan lebar $2 \frac{1}{2}$ inch untuk kapasitas $400 \mathrm{~kg}-500 \mathrm{~kg}$, tipe II rol dengan lebar 4 inch (lubang kecil) untuk kapasitas $700-800 \mathrm{~kg}$ gabah/jam, tipe III rol dengan lebar 4 inch (lubang besar) untuk kapasitas 800 $1000 \mathrm{~kg}$ gabah/jam dan tipe IV rol dengan lebar 6 inch untuk kapasitas 900 - $1250 \mathrm{~kg}$ gabah/jam.

Adapun warna rol karet umumnya abu-abu, hijau gelap dan coklat. 
Sesuai dengan fungsinya maka rol karet harus mempunyai faktor penentu mutu yang menjamin penggunaannya.

Menurut I.S 8427 - 1977, Spesification For Rubber Roll For Paddy Dehusker, persyaratan untuk rol karet ditetapkan bagi 2 tipe ro yaitu rol karet warna hitam ( tipe A ) dan rol karet warna putih atau warna lain selain hitam ( tipe B), sebagai berikut :

Tegangan putus ditetapkan minimum sebesar $11,8 \mathrm{MPa} \quad(11,8$ $\left.\mathrm{N} / \mathrm{mm}^{2}\right)$ untuk rol tipe $\mathrm{A}$ dan $8,8 \mathrm{MPa}\left(8,8 \mathrm{~N} / \mathrm{mm}^{2}\right)$ untuk rol tipe $\mathrm{B}$, sedangkan perpanjangan putus ditentukan minimum sebesar $150 \%$ dan $130 \%$ untuk rol tipe A dan tipe B. Kekerasan untuk kedua tipe rol ditentukan antara 80 - 95 IRHD, sedangkan penurunan kekerasan setelah pengusangan pada suhu $80 \pm 2{ }^{\circ} \mathrm{C}$ tidak boleh lebih dari 10 IRHD. Ketahanan kikis dinyatakan pula sebagai faktor penentu mutu yang penting dan perlu diteliti.

\section{METODE PENELITIAN}

\section{A. Bahan dan peralatan}

1. Bahan-bahan

8 buah merk rol karet gilingan padi dengan ukuran lebar rol meliputi $2 \frac{1}{2} "$, 4" dan 6", warna abu-abu, hijau gelap dan coklat.

2. Peralatan

a. Alat ukur tebal ( mikrometer) dengan ketelitian $0,05 \mathrm{~mm}$

b. Alat uji kuat tarik dan mulur ( tensile strength tester)

c. Alat uji kekerasan (Durometer A )

d. Buffing machine

e. Pisau

\section{B. Prosedur penelitian}

Sebelum dilakukan pengujian, cuplikan dikondisikan dahulu dalam ruangan yang mempunyai suhu $27 \pm 2^{\circ} \mathrm{C}$ dan kelembaban relacif $65 \pm 5 \%$ selama minimal 16 jam.

1. Pengujian rol karet meliputi :

a. Tebal

Pisahkan terlebih dahulu bagian lapisan karet dari rol logam. Ukur tebal lapisan karet termasuk bagian alurnya pada 5 titik yang berbeda, dengan mempergunakan mikrometer yang mempunyai ketelitian 0,05 $\mathrm{mm}$.

Perbedaan tebal lapisan karet dari ke 5 titik tidak lebih atau kurang dari $0,05 \mathrm{~mm}$. b. Tegangan putus dan perpanjangan putus

Potong cuplikan dari ketiga bagian lapisan karet pada rol yakni dari bagian luar, tengah dan bagian dalam, dengan yaknis dengan arah alur arah garis dari ujung ke ujung segaris ala dan lakuan pada permukaan rol. Jepit cuplikan pada alat dan lakukan penarikan dengan kecepatan $500 \mathrm{~mm} /$ menit. Catat beban
maksimum yang diperlukan untuk menarik cuplikan sampai putus.

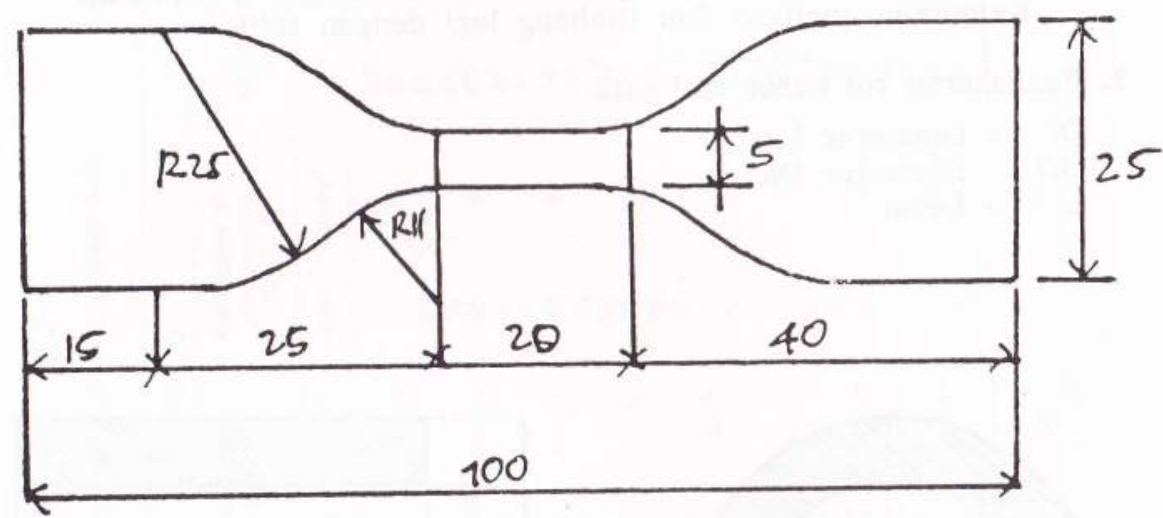

Gambar 1 : Bentuk dan ukuran cuplikan.

\section{c. Kekerasan}

Ukur kekerasan rol pada berbagai titik yang berbeda dari bagian lapisan karet rol dengan mempergunakan Durometer A.

Catat kekerasan dari hasil pengukuran tersebut.

Selanjutnya masukkan cuplikan kedalam oven dengan sirkulasi udara pada suhu $80 \pm 2^{\circ} \mathrm{C}$ selama 2 jam.

Keluarkan cuplikan dan segera ukur kembali kekerasannya dengan mempergunakan Durometer A. 


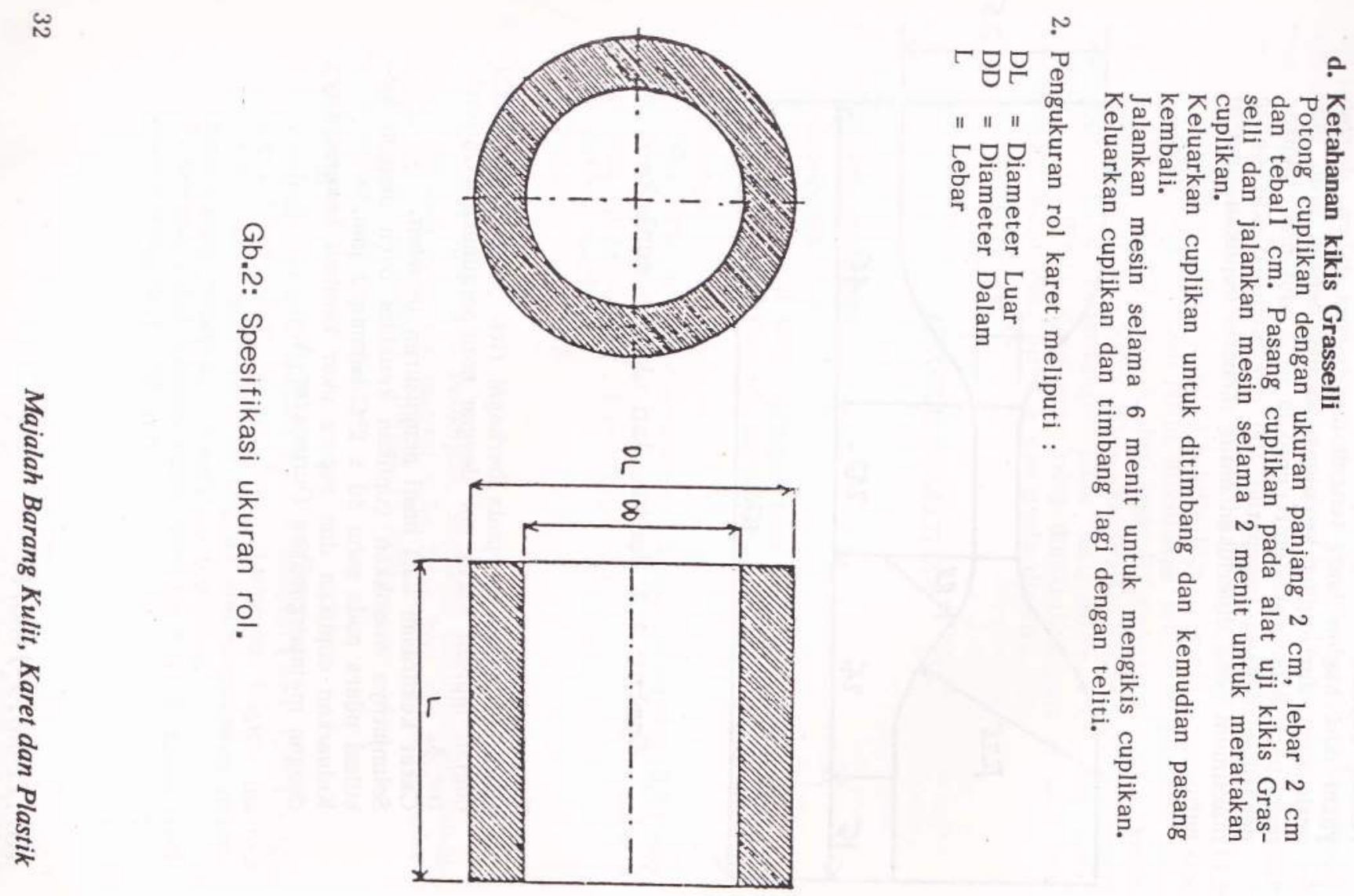

ב⿱

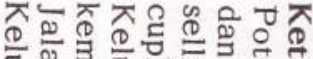

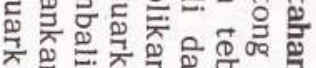
근 웜

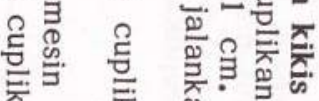
$\stackrel{\leftrightarrow}{0}$ प्र०ิ? $\exists 0$ の त

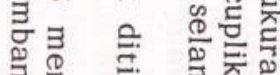
政 No 릊 寻 $\exists \quad \exists \frac{N}{2}$

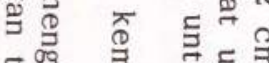

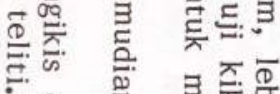

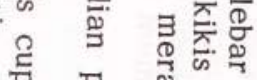

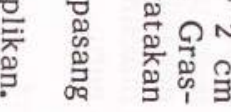

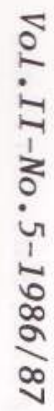

C. HASIL PENELITIAN DAN PEMBAHASAN

I. Hasil-hasil penelitian seperti tertera dalam tabel 1 an tabel 2.

Tabel 1. Hasil pengujian sifat fisika rol karet gilingan padi.

\begin{tabular}{|c|c|c|c|c|c|c|c|c|c|c|c|c|c|c|}
\hline \multirow{3}{*}{ No. } & \multirow{3}{*}{ Kode } & \multirow{3}{*}{ Ulangan } & \multicolumn{12}{|c|}{ Hasil uji } \\
\hline & & & \multicolumn{2}{|c|}{$\begin{array}{l}\text { Tebal } \\
(\mathrm{mm})\end{array}$} & \multicolumn{2}{|c|}{$\begin{array}{c}\text { Tegangan putus } \\
\left(\mathrm{N} / \mathrm{mm}^{2}\right)\end{array}$} & \multicolumn{2}{|c|}{$\begin{array}{c}\text { Perpanj. putus } \\
(\%)\end{array}$} & \multicolumn{2}{|c|}{$\begin{array}{l}\text { Kekerasan sbl. } \\
\text { pengusangan } \\
\text { Shore A }\end{array}$} & \multicolumn{2}{|c|}{$\begin{array}{l}\text { Kekerasan sdh. } \\
\text { pengusangan } \\
\text { Shore A }\end{array}$} & \multicolumn{2}{|c|}{$\begin{array}{c}\text { Ket. kikis } \\
\text { Grasselli } \\
\left(\mathrm{mm}^{3} / \mathrm{kgm}\right)\end{array}$} \\
\hline & & & Data & Rata $^{2}$ & Data & Rata $^{2}$ & Data & Rata $^{2}$ & Data & Rata $^{2}$ & Data & Rata $^{2}$ & Data & Rata $^{2}$ \\
\hline \multirow[t]{3}{*}{1.} & SIA & 1. & 20,13 & & 14,54 & & 232 & & 85 & & 80 & & 0,13 & \\
\hline & & 2. & 20,12 & 20,12 & 13,50 & 13,91 & 228 & 231,33 & 85 & 85 & 80 & 80 & 0,14 & 0,14 \\
\hline & & 3. & 20,11 & & 13,68 & & 234 & & 85 & & 80 & & 0,15 & \\
\hline \multirow[t]{3}{*}{2.} & INK & 1. & 20,51 & & 13,83 & & 346 & & 85 & & 80 & & 1,14 & \\
\hline & & 2. & 20,50 & 20,50 & 12,82 & 13,33 & 284 & 311,33 & 85 & 85 & 80 & 80 & 1,13 & 1,14 \\
\hline & & 3. & 20,49 & & 13,33 & & 304 & & 85 & & 80 & & 1,15 & \\
\hline \multirow[t]{3}{*}{3.} & PAJ & 1. & 19,60 & & 15,20 & & 140 & & 95 & & 90 & & 0,03 & \\
\hline & & 2. & 19,60 & 19,60 & 15,17 & 15,20 & 150 & 150,00 & 95 & 95 & 90 & 90 & 0,04 & 0,03 \\
\hline & & 3. & 19,60 & & 15,62 & & 160 & 150,00 & 95 & & 90 & & 0,02 & \\
\hline \multirow[t]{3}{*}{4.} & IND & 1. & 18,28 & & 11,22 & & 50 & & 95 & & 92,5 & & 0,21 & \\
\hline & & 2. & 18,30 & 18,29 & 13,71 & 13,16 & 60 & 58,0 & 95 & 95 & 92,5 & 92,5 & 0,23 & 0,22 \\
\hline & & 3. & 18,29 & & 14,13 & & 64 & & 95 & & 92,5 & $\sqrt{2,}$, & 0,22 & \\
\hline \multirow[t]{3}{*}{5.} & HOR & 1. & 17,55 & & 14,52 & & 294 & & 90 & & 87,5 & & 0,73 & \\
\hline & & 2 . & 17,55 & 17,55 & 9,66 & 11,78 & 210 & 228,0 & 90 & 90 & 87,5 & 87,5 & 0,72 & 0,72 \\
\hline & & 3. & 17,55 & & 11,7 & & 180 & & 90 & & 87,5 & & 0,71 & \\
\hline \multirow[t]{3}{*}{6.} & STA & 1. & 21,51 & & 7,54 & & 136 & & 95 & & 92,5 & & 0,25 & \\
\hline & & 2. & 21,49 & 21,50 & 10,58 & 8,95 & 160 & 154,0 & 95 & 95 & 92,5 & 92,5 & 0,26 & 0,25 \\
\hline & & 3. & 21,50 & & 82,53 & & 166 & & 95 & & 92,5 & & 0,24 & \\
\hline \multirow[t]{3}{*}{7.} & PAM & 1. & 22,0 & & 17,88 & & 126 & & 95 & & 90 & & 0,37 & \\
\hline & & 2. & 22,0 & 22,0 & 19,38 & 19,10 & 158 & 142,67 & 95 & 95 & 90 & 90 & 0,38 & 0,37 \\
\hline & & 3. & 22,0 & & 20,03 & & 144 & & 95 & & 90 & & 0,36 & \\
\hline \multirow{4}{*}{8.} & FLY & 1. & 21,00 & & 12,65 & & 124 & & 90 & & 85 & & 0,59 & \\
\hline & & 2. & 20,99 & 21,00 & 16,38 & 14,56 & 224 & 184 & 90 & 90 & 85 & 85 & 0,57 & 0,58 \\
\hline & & 3. & 21,01 & & 14,66 & & 204 & 104 & 90 & & 85 & & 0,58 & \\
\hline & & & & $\begin{array}{c}x=20,07 \\
S d= \\
\pm 1,53\end{array}$ & & $\begin{array}{c}x=13,75 \\
S d= \\
\pm 2,90\end{array}$ & & $\begin{array}{c}x=182,42 \\
S d= \\
\pm 75,60\end{array}$ & & $\begin{array}{c}x=91,25 \\
S d= \\
\pm 4,43\end{array}$ & & $\begin{array}{c}x=87,18 \\
S d= \\
\pm 5,08\end{array}$ & & $\begin{array}{c}x=0,43 \\
S d= \\
\pm 0,36\end{array}$ \\
\hline
\end{tabular}


Min I In

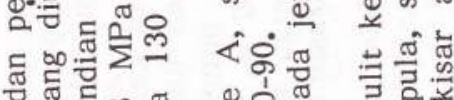

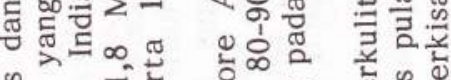

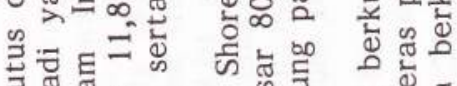

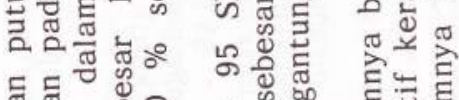

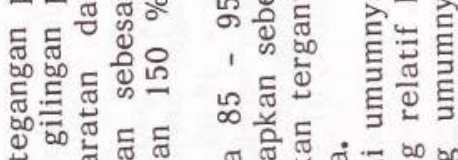
—

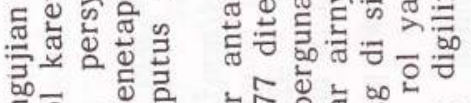

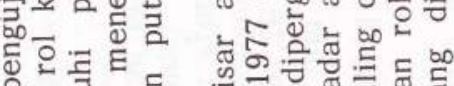
உ 穴

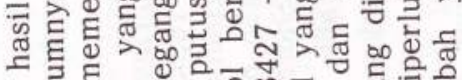
- EN EN 瓷

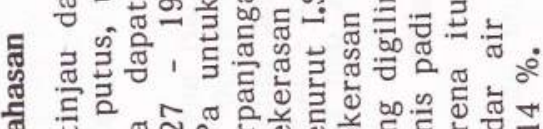

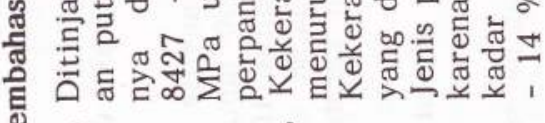
ए.

i

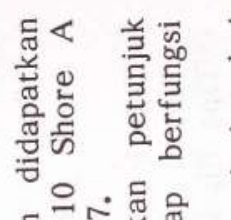

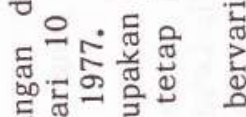

ॠ్

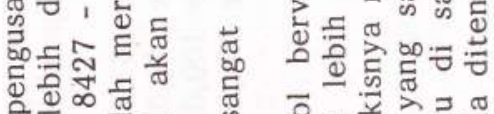

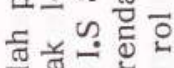

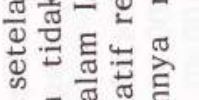

둔 둥 $\frac{\pi}{0}$

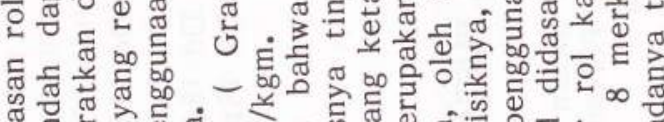

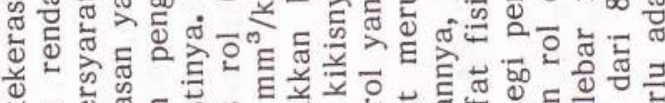

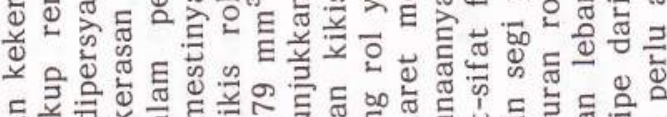

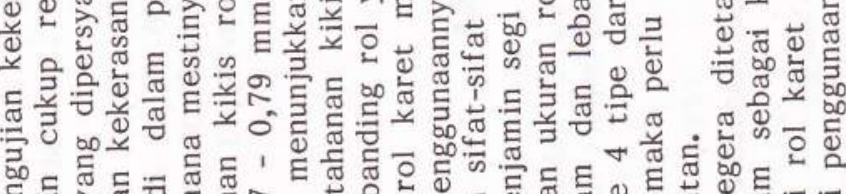

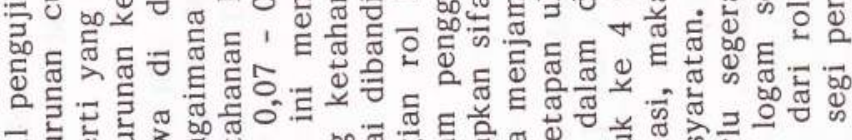

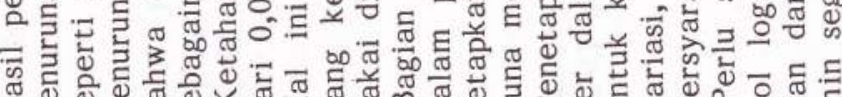

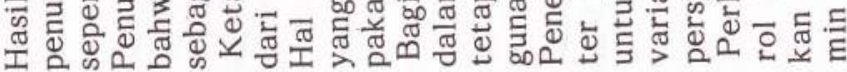
लं

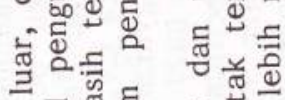

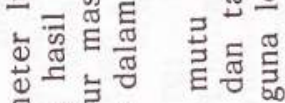

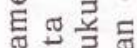
동. 을 तु त. 空: 줄 들 $\stackrel{0}{\circ}$ 此

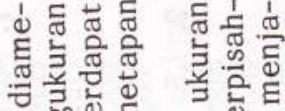

\begin{tabular}{|c|c|c|c|c|c|c|c|c|c|c|c|}
\hline \multirow{2}{*}{ No. } & \multirow{2}{*}{ Ukuran } & \multirow{2}{*}{ Tipe } & \multirow{2}{*}{ Ulangan } & \multicolumn{8}{|c|}{$\mathrm{K} \circ \mathrm{de}$} \\
\hline & & & & SIA & INK & PAJ & IND & HOR & STA & PAM & FLY \\
\hline \multirow[t]{12}{*}{1.} & Lebar & $2 \frac{1}{2} "$ & 1. & 63,72 & 63,50 & 63,22 & 63,54 & 64,02 & 63,22 & 61,00 & 63,72 \\
\hline & & & 2. & 63,72 & 63,50 & 63,22 & 63,54 & 64,02 & 63,22 & 61,00 & 63,72 \\
\hline & & & 3. & 63,72 & 63,50 & 63,22 & 63,54 & 64,02 & 63,22 & 61,00 & 63,72 \\
\hline & & $4 "$ & 1. & 100,10 & 100,30 & 100,20 & 100,10 & 100,10 & 100,00 & 100,00 & 100,00 \\
\hline & & lubang kecil & 2. & 100,10 & 100,30 & 100,20 & 100,10 & 100,10 & 100,00 & 100,00 & 100,00 \\
\hline & & & 3. & 100,10 & 100,30 & 100,20 & 100,10 & 100,10 & 100,00 & 100,00 & 100,00 \\
\hline & & $4 "$ & 1. & 100,00 & 100,20 & 100,10 & 100,40 & 100,20 & 100,10 & 100,20 & 100,30 \\
\hline & & lubang besar & 2. & 100,00 & 100,20 & 100,10 & 100,40 & 100,20 & 100,10 & 100,20 & 100,30 \\
\hline & & & 3. & 100,00 & 100,20 & 100,10 & 100,40 & 100,20 & 100,10 & 100,20 & 100,30 \\
\hline & & $6 "$ & 1. & 152,00 & 151,60 & 151,40 & 151,30 & 151,70 & 150,00 & 152,00 & 151,50 \\
\hline & & & 2. & 152,00 & 151,60 & 151,40 & 151,30 & 151,70 & 150,00 & 152,00 & 151,50 \\
\hline & & & 3. & 152,00 & 151,60 & 151,40 & 151,30 & 151,70 & 150,00 & 152,00 & 151,50 \\
\hline \multirow[t]{12}{*}{2.} & Diameter & $2 \frac{1}{2} "$ & 1. & 116,82 & 116,76 & 126,80 & 119,42 & 118,70 & 118,60 & 118,80 & 118,50 \\
\hline & dalam & & 2. & 116,82 & 116,76 & 126,80 & 119,42 & 118,70 & 118,60 & 118,80 & 118,50 \\
\hline & & & 3. & 116,82 & 116,76 & 126,80 & 119,42 & 118,70 & 118,60 & 118,80 & 118,50 \\
\hline & & $4^{\prime \prime}$ & 1. & 129,00 & 128,00 & 127,00 & 130,00 & 129,00 & 130,00 & 130,00 & 130,00 \\
\hline & & lubang kecil & 2. & 129,00 & 128,00 & 127,00 & 130,00 & 129,00 & 130,00 & 130,00 & 130,00 \\
\hline & & & 3. & 129,00 & 128,00 & 127,00 & 130,00 & 129,00 & 130,00 & 130,00 & 130,00 \\
\hline & & $4 "$ & 1. & 182,00 & 182,00 & 182,00 & 182,00 & 183,00 & 182,00 & 182,00 & 182,00 \\
\hline & & lubang besar & 2. & 182,00 & 182,00 & 182,00 & 182,00 & 183,00 & 182,00 & 182,00 & 182,00 \\
\hline & & & 3. & 182,00 & 182,00 & 182,00 & 182,00 & 183,00 & 182,00 & 182,00 & 182,00 \\
\hline & & $6 "$ & 1. & 182,00 & 182,00 & 182,00 & 181,00 & 182,00 & 181,00 & 182,00 & 182,00 \\
\hline & & & 2. & 182,00 & 182,00 & 182,00 & 181,00 & 182,00 & 181,00 & 182,00 & 182,00 \\
\hline & & & 3. & 182,00 & 182,00 & 182,00 & 181,00 & 182,00 & 181,00 & 182,00 & 182,00 \\
\hline \multirow[t]{12}{*}{3.} & Diameter & $2 \frac{1}{2} "$ & 1. & 157,00 & 157,00 & 160,00 & 156,00 & 153,80 & 158,00 & 159,00 & 158,00 \\
\hline & & & 2. & 157,00 & 157,00 & 160,00 & 156,00 & 153,80 & 158,00 & 159,00 & 158,00 \\
\hline & & & 3. & 157,00 & 157,00 & 160,00 & 156,00 & 153,80 & 158,00 & 159,00 & 158,00 \\
\hline & & $4 "$ & 1. & 171,00 & 170,00 & 170,00 & 169,00 & 170,00 & 171,00 & 171,00 & 170,00 \\
\hline & & lubang kecil & 2. & 171,00 & 170,00 & 170,00 & 169,00 & 170,00 & 171,00 & 171,00 & 170,00 \\
\hline & & & 3. & 171,00 & 170,00 & 170,00 & 169,00 & 170,00 & 171,00 & 171,00 & 170,00 \\
\hline & & $4 "$ & 1. & 225,00 & $22 €, 00$ & 226,00 & 225,00 & 225,00 & 226,00 & 227,00 & 226,00 \\
\hline & & lubang besar & 2. & 225,00 & 226,00 & 226,00 & 225,00 & 225,00 & 226,00 & 227,00 & 226,00 \\
\hline & & & 3. & 225,00 & 226,99 & 226,00 & 225,00 & 225,00 & 226,00 & 227,00 & 226,00 \\
\hline & & $6 "$ & 1. & 224,00 & 224,00 & 226,00 & 225,00 & 225,00 & 225,00 & 226,00 & 224,00 \\
\hline & & & 2. & 224,00 & 224,00 & 226,00 & 225,00 & 225,00 & 225,00 & 226,00 & 224,00 \\
\hline & & & 3. & 224,00 & 224,00 & 226,00 & 225,00 & 225,00 & 225,00 & 226,00 & 224,00 \\
\hline
\end{tabular}




\section{KESIMPULAN}

Dari hasil penelitian dan analisa data yang dilakukan, maka dapat disimpulkan bahwa :

1. Mutu rol karet gilingan padi masih bervariasi, dari analisa data diperoleh hasil sebagai berikut : tebal 18,53 - 21,60 mm, tegangan putus $10,85-16,65 \mathrm{~N} / \mathrm{mm}^{2}$, perpanjangan putus 106,80 - 258,02 \%, kekerasan sebelum pengusangan 86,82 - 95,68 Shore A, setelah pengusangan $82,10-92,26$ Shore A dan ketahanan kikis Grasselli sebesar $0,07-0,79 \mathrm{~mm}^{3} / \mathrm{kgm}$.

2. Spesifikasi teknis rol didasarkan pada faktor-faktor sesuai dengan penggunaannya.

3. Rol karet gilingan padi umumnya terdapat dalam warna selain hitam seperti abu-abu, hijau tua, coklat.

4. Ukuran rol umumnya terdapat dalam 4 tipe sesuai kapasitas mesin yang diproduksi sebagai berikut : satuan dalam $\mathrm{mm}$

Tipe I , Lebar 63,22- 64,02 Dd 116,76-126,80 DI 157,0-160,0 Tipe II, Lebar $100,00-100,30$ Dd $127,00-130,00$ Dl $169,0-171,0$ Tipe III, Lebar $100,00-100,40$ Dd $182,00-185,00$ Dl $225,0-227,0$ Tipe IV, Lebar $150,00-152,00$ Dd $181,00-182,00$ Dl $224,0-226,0$

\section{DAFTAR PUSTAKA}

1. Annonimous

Buku petunjuk pemakaian II Mesin kupas gabah Rice Huller Quik. Pabrik Mesin Alat-alat Pertanian-Import dan Dealer Kubota CV. Karya Hidup Santosa Yogyakarta

2. I.S. $8427-1977$

Specification For Rubber Roll For Paddy Dehusker.

Indian Standards Institution.

Manak Bhavan, 9 Bahadur Shah Zafar Marg New Delhi

3. JIS B 9124 - 1963

Rice hulling rubber rolls

Japanese Industrial Standards Committee
PENELITIAN PEMBUATAN KOMPON PVC

UNTUK BAHAN. BANGUNAN (ENTERNIT PVC)

DENGAN VARIASI FILLER SERAT BATANG PISANG DAN Ca $\mathrm{CO}_{3}$

Oleh : Kelompok Peneliti Proses Produksi Barang Plastik *

\section{ABSTRACT}

This research is an experiment which use plastic material for making enternit. The plastic material is made of PVC resin for 35 phr., EPO 5 phr., BaCdZn 100 phr. by adding ingredients 3.5 phr., Stearic Acid 0.75 phr., $\mathrm{CaCO}_{3}$ varied $50-90$ phr., and fibre of banana stem 20-40 phr. The experiment result prove that the PVC plastic material can made enternit sheet. The opthe PVC comtimum value of phich using $\mathrm{CaCo}_{3} 90 \mathrm{phr}$. and banana stem $40 \mathrm{phr}$.

\section{PENDAHULUAN}

1. Latar Belakang.

Enternit yang dipergunakan sebagai bahan bangunan, saat ini dibuat dari bahan campuran semen. Sesuai dengan perkembangan industri dewasa ini Indonesia telah mampu memproduksi PVC dat dalam jum sebagai bahan untuk pemsehingga apabila

buatan plafon, cukup terjamin pengadaannya. Sampai saat ini penelitian mengenai penggunaan PVC

bahan baku pembuatan enternit belum pernah dilakukan. Sebagai bahan pembuat bahan bangunan (entern agar didapat harus dicampur dengan ingredient-ingredient lain agar didapat sifat-sifat yang lebih baik. Karena enternit harus bersifat keras dan kaku maka pada pvc harus ditambahkan filler yang dapat memperbaiki kekerasan.

Oleh karena itu perlu dilakukan penelitian kemungkinan pembuatan kompon PVC untuk bahan bangunan enternit, dengan variasi filler serat batang pisang dan $\mathrm{CaCO}_{3}$.

2. Tujuan Penelitian.

Untuk mengetahui kemungkinan penggunaan PVC sebagai bahan baku pembuatan enternit.

3. Sasaran Penelitian.

Mendapatkan kompon PVC untuk bahan bangunan enternit yang memenuhi persyaratan.

*)1.Ir. Siti Rochani, 2.Dra. Supraptiningsih, 3.Sofyan Karani,B Sc.,

4.Sunarso, 5.Hernadi Surip,B Sc., 6.Suyat ini, 7.Nurwachid Sahadi.

Vol.II-No. 5-1986/87 